\title{
Government: where does nutrition policy come from?
}

\author{
BY M. J. WISEMAN \\ Nutrition Unit, Department of Health, Room C307, Alexander Fleming House, Elephant and \\ Castle, London SEI 6BY
}

In order to answer the question in the title, I will spend a little time simply describing structures within Government Departments in the UK which deal with nutrition, and how they interact with other Government Departments and Divisions and outside agencies. However, there is a simple and short answer to the question. Policy on any issue in a Government Department is determined by Ministers. Each Government is elected at a General Election, and in the run up to that Election, many issues will be debated in the public arena. There will be little doubt in the minds of the public about the general philosophy of the Government that has been elected, and indeed of its specific intentions in a number of areas. Although there will be many areas which have not been debated in public, it is understood that the general philosophy of the Government will apply to those areas as much as any other. Consequently, nutrition policy in general, like all other policies, is detcrmined in the light of a philosophy directly determined by the outcome of the electoral process. Nevertheless within that general philosophy many practical details exist. In respect of these details Ministers decide on policy in the light of advice.

Advice to Ministers in the field of nutrition has been forthcoming ever since there was such a field. In its most formal guise, such advice takes the form of a report from the Chief Medical Officer to Ministers. However, there is an extensive structure of civil servants beneath the Minister which contributes to less formal advice. In the Department of Health there are two parallel lines of hierarchy, headed by the Permanent Secretary, comprising on the one side the administrative divisions and on the other the Chief Medical Officer and his professionals. Within that structure there exists a focus for nutrition (Fig. 1). The Nutrition Unit is a small group of professionals: doctors and a nutritionist. This professional branch and its analogous administrative branch work together as a single unit. They are responsible for liaison with senior colleagues, with other divisions in the same Department, and with other Government Departments which may have an interest in nutritional matters. In an area like nutrition, as in any other specialist scientific field, access to the knowledge and expertise of the scientific community is necessary. This is provided by the Committee on Medical Aspects of Food Policy (COMA; Fig. 2). The function of COMA is to advise the Chief Medical Officer, and its structure is flexible enough to respond to changing needs. At any one time its ad hoc sub-committees and panels reflect areas of current concern. For instance, the major review currently being undertaken on recommended daily amounts of food energy and nutrients was a response to a perceived need for a new look at this aspect of nutrition. Once COMA existed, the Nutrition Unit, which services it, became the natural focus for input into the Department on nutrition matters, and links to a more or less formal extent have now been established between the Unit and most bodies with an interest (Fig. 3).

There are a number of influences on policy development. First there is the essential database of the scientific literature. This is the bedrock of COMA's advice. There are 


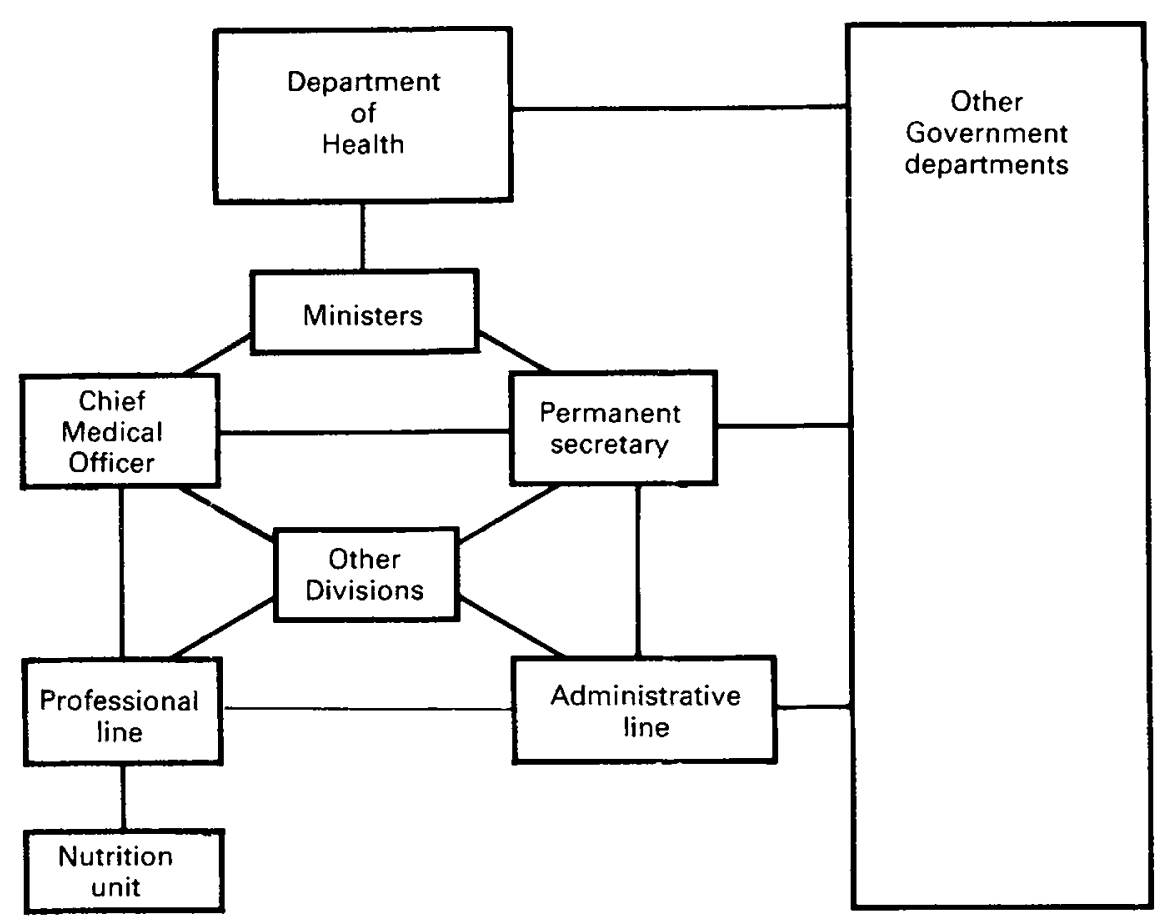

Fig. 1. Lines of communication in the Department of Health.

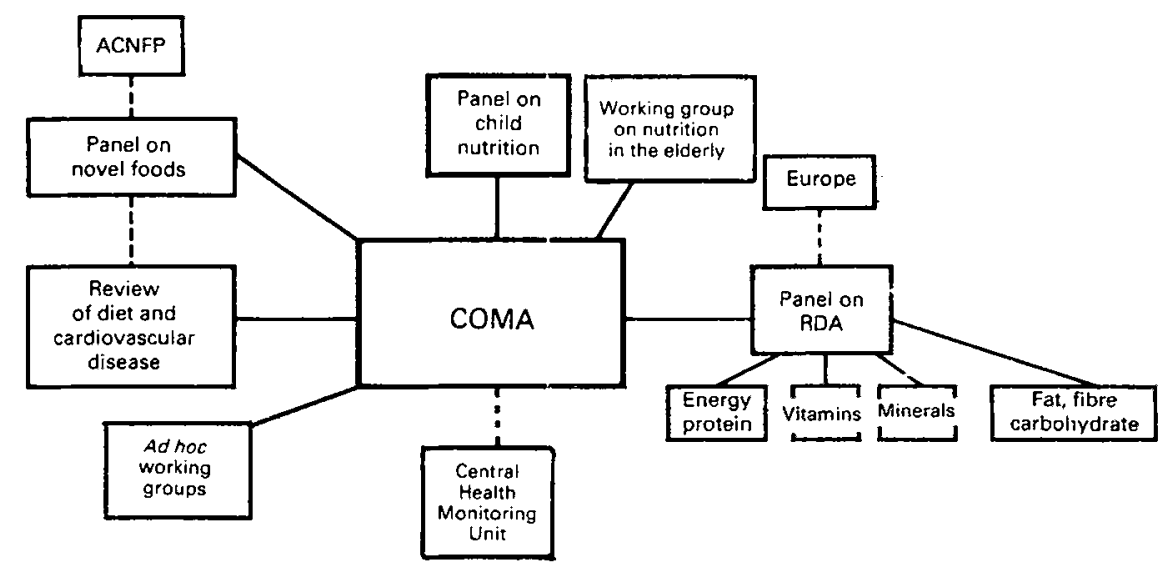

Fig. 2. Network of independent expert advice in nutrition. COMA, Committee on Medical Aspects of Food Policy; RDA, recommended daily amounts of food energy and nutrients; ACNFP. Advisory Committee on Novel Foods and Processes.

nevertheless many questions to which the scientific literature does not provide an answer. Opinion about these issues may be at least as strong as ones for which there is a greater scientific basis, and the public and the media may play a substantial role in 


\section{DH NUTRITION UNIT}

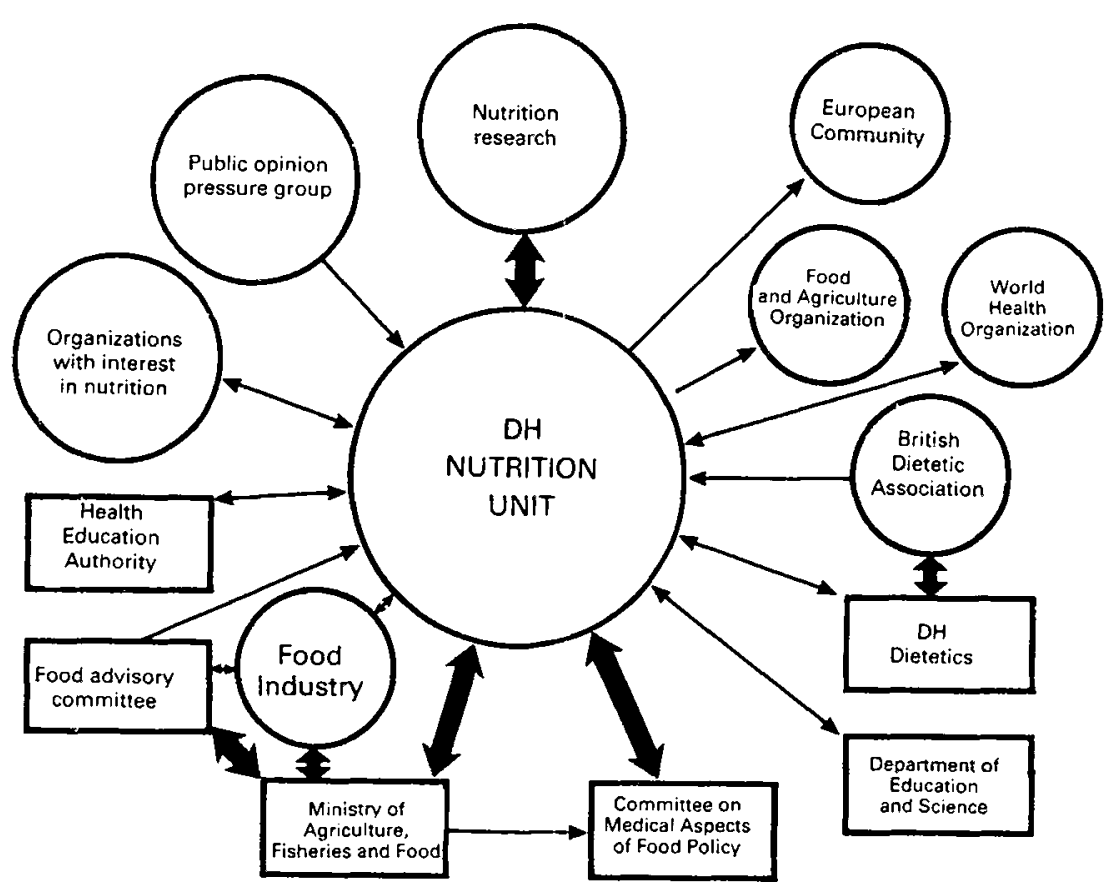

Fig. 3. Interactions of the Department of Health (DH) Nutrition Unit.

attempting to influence policy here. There are also a number of pressure groups who wish to influence policy. Pressure groups are not necessarily, as the term might imply, irresponsible "activists' but often comprise a number of highly eminent and responsible members of the scientific community. A feature which is common to most pressure groups is that they are 'single issue' groups. Often their objectives will be identical with those of the Government, but the Government's wider responsibilities may preclude it from taking the courses advocated. The problem identified by the pressure group is often very real, but sometimes scen in isolation.

The general philosophy of the current administration is very much that responsibility should lie with the individual. This means that the individual should be able to make an informed choice for his or her diet. In order for any choice to be informed, there must be enough information available, and the individual must be educated to interpret that information usefully. The provision of one of these out of step with the other can only lead to problems. Responsibility within the Government for allowing the informed choice of individuals lies mainly with three Departments: the Ministry of Agriculture, Fisheries and Food (MAFF), the Department of Health, including the Health Education Authority, and the Department of Education and Science (DES). The DES, as well as being responsible for school and higher education, also provides the funds for the Medical Research Council. It is the responsibility of MAFF to ensure that a choice is available by ensuring a plentiful supply of wholesome food at affordable prices. From this main responsibility are derived its others such as monitoring the nation's diets, and 


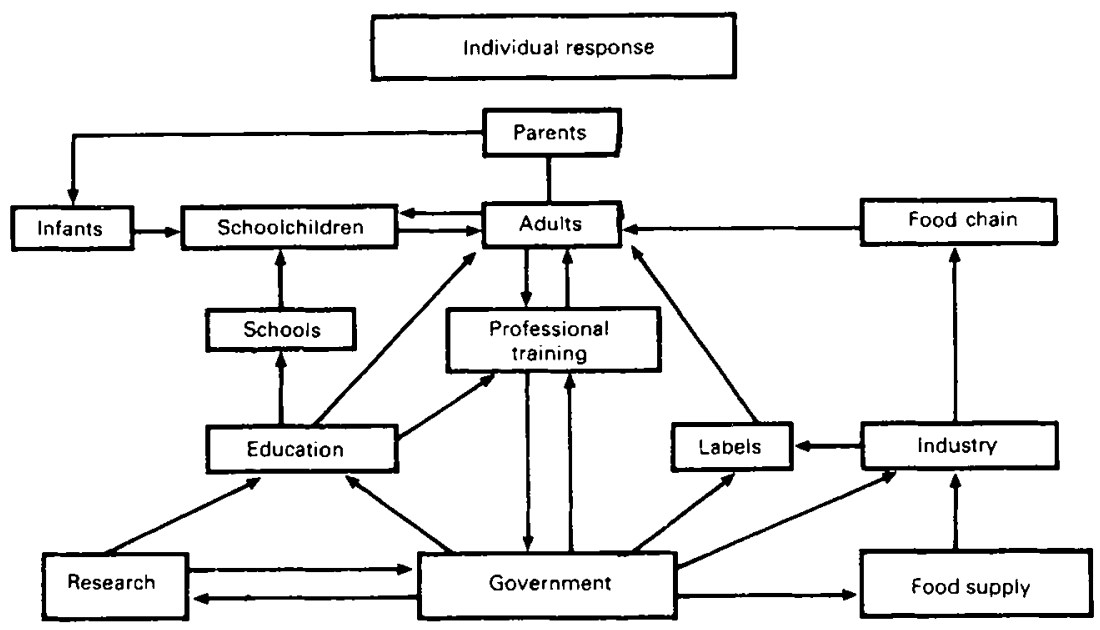

Outside influence

Fig. 4. Pathways of information affecting consumers. The effects of activity along any pathway will vary according to the individual's response, and may be modified by unavoidable external influences.

responsibility for food legislation. The Department of Health is responsible for development of the messages which the individual will be able to use and provides advice on the scientific basis of the relationship between nutrition and health. The Health Education Authority is responsible for transmitting that information to the public. There is, therefore, a very diverse framework of information feeding eventually on to consumers, be they infants, schoolchildren or adults, ranging from basic research through education, through legislation on labelling, and through food supply and industry, many but not all of which will be under some influence of Government. The whole framework is subsumed within the context of outside influences such as European legislation, and media influences and individuals' responses to them (Fig. 4).

Any policy requires an input of information relevant to the issue. The relationship between nutrition and health is central, and information on this is provided by research at all levels from cellular biology upwards. In order to apply that appropriately it is equally important to have information on the nutritional status quo. This is provided by surveillance. Each of these may provide opportunities for the other. The output of nutrition policy is essentially the provision of information via labelling and education. Some would argue that more persuasive methods of promoting particular changes or attitudes are worthwhile too. This is very much an area where political as well as scientific issues are likely to be involved. However, there are few notions in the input side that are so universally acknowledged that they do not provoke any arguments, and a degree of judgement is required in determining the currently perceived truth of any particular matter. Evidently, different bodies may come to different decisions. Even given the acceptance of some associations between nutrition and health, a further judgement has to be made to decide when that evidence is strong enough to trigger an intervention; that is, output. It is essential that such triggers are based on sound scientific 
bases. In the clinical field many policies which were standard in the past, on the basis of 'common sense', have been found wanting when put to the test, such as prolonged bed rest following a heart attack. In relation to nutrition there are a number of problems which, if not specific to it, are nevertheless very important. The relationship between nutrition and health is in general a very long-term one. Studies which have addressed nutritional problems over a time-span approaching that for which many nutrition-related disease develop are few and far between.

Similarly there is difficulty in measuring the status quo. We do not have useful markers of body status for many nutrients and the measurement of dietary intakes even over as short a period as a few days is fraught with difficulty. This is apparent from the proxies which are used such as household purchase surveys. In this vacuum, the National Food Survey provides an extremely valuable source of information, and a recent dietary and nutritional survey of British adults, performed by the Office of Population Censuses and Surveys on behalf of MAFF and the Department of Health wili provide an invaluable archive of the current situation. Nevertheless the question still remains as to when an intervention should take place and then what that intervention should be. This depends to some extent on the degree of certainty with which the relationship between nutrition and health has been established. Because of different perceptions of the degree of certainty, even between experts, there are bound to be different opinions about what form the intervention should take. Should labelling on food give no information at all, or all the information that could possibly be given? Almost certainly neither of those extremes would be useful and the question then arises as to where in between the correct balance lies. Similarly with regard to education, identification of target groups, and putting into priority order the messages which they should receive, require judgements. The more forceful or persuasive an intervention, the more certain one must be about its value. Conversely most of the messages that one would like to convey relating to nutrition cannot be summed up in a few words and it is almost a direct competition between accuracy and simplicity of information. Examples of rather simple but misleading information can be found frequently in the national press and in magazines. The press may take some preliminary information from scientific meetings and interpret it on behalf of their readers. Of course basic science has an important role to play in developing the messages for the public, but this takes time. The process of repeat experiments, of consensus development, followed by accurate publicity provides a iess seductive but more authoritative basis for the public to use. The key lies with links being forged between responsible interested partics. There should be communication between the Research Councils and Government Bodies, and industry. There is currently a proposal from the Medical Research Council that a Forum should be set up to coordinate research across these broad sectors. Liaison between Government Departments responsible for food and nutrition is good and a formal group to coordinate activities in the fields of research, surveillance, and education has already been set up. In order to make sensible decisions within this structure, we need information on what people eat, why they eat it, and how it affects them. The better that information system, the better the decisions that will be taken. 